The Effect of Peat on the Transpiration and Growth of Certain Plants

Author(s): Kathleen M. Thatcher

Source: Journal of Ecology, Vol. 9, No. 1 (Sep., 1921), pp. 39-59

Published by: British Ecological Society

Stable URL: http://www.jstor.org/stable/2255759

Accessed: 26-06-2016 12:50 UTC

Your use of the JSTOR archive indicates your acceptance of the Terms \& Conditions of Use, available at

http://about.jstor.org/terms

JSTOR is a not-for-profit service that helps scholars, researchers, and students discover, use, and build upon a wide range of content in a trusted digital archive. We use information technology and tools to increase productivity and facilitate new forms of scholarship. For more information about JSTOR, please contact support@jstor.org.

Wiley, British Ecological Society are collaborating with JSTOR to digitize, preserve and extend access to Journal of Ecology 


\title{
THE EFFECT OF PEAT ON THE TRANSPIRATION AND GROWTH OF CERTAIN PLANTS
}

\author{
By KATHLEEN M. THATCHER.
}

(With six Figures in the Text.)

\section{INTRODUCTION.}

The question of the cause of the xerophytic characters exhibited by plants growing in acid peat bogs has been the subject of much discussion, but so far no entirely satisfactory solution has been brought forward.

Two main views are held. Transeau $(\mathbf{1 6}, \mathbf{1 7})$ and others contend that the chemical and physical data now to hand do not account for the differences between bog and swamp vegetation-that "bog plants are due to past history and where disturbed they give place to swamp associations." The second view - that held by the majority of writers-is that the xerophily is necessitated by the physical, chemical and biological conditions in which the plants are growing.

Of these conditions, low oxygen content of the soil (Dachnowski, 8), low aeration (Transeau, 16, 17; Dachnowski, 8), root excretions (Livingston), bog toxins (Dachnowski, 8), low temperature of soil water (Transeau, 16, 1 7), biological soil processes (Dachnowski, 8) and winter conditions (Gates, 9), have been suggested as factors which, by causing a low rate of absorption make a low rate of transpiration essential. Schröter ${ }^{1}$ had previously called attention to the poorly developed root systems of bog plants which might well be correlated with a low rate of absorption, and itself be the result of one or more of the factors mentioned.

Most of these conditions can be grouped together as affecting the amount of available water in the peat soil. If mesophytic plants grown in an acid peat medium can absorb sufficient water to balance their transpiration under conditions such as are met with in peat bogs, then "xerophilous" structure regarded as a means of checking water loss by transpiration cannot be considered a necessary adaptation in a peat of community. If, on the other hand, mesophytic plants grown under such conditions are unable to absorb sufficient water to balance their transpiration, then "xerophytic" characters may fairly be regarded as essential to bog plants. It was thought that a careful comparison between the rates of transpiration of plants grown in peat and in garden soil might help to elucidate the question.

\footnotetext{
1 Früh and Schröter. Die Moore der Schweiz. Bern, 1903.
} 
The work has been carried out in the Botanical Department of the Victoria University of Manchester, with the aid of a grant from the Department of Scientific and Industrial Research and a Scholarship from the University.

My thanks are due to Prof. Weiss and to Mr Adamson for their valuable suggestions and criticism throughout the course of the work and also to $\mathrm{Mr}$ Thatcher, who has rendered great assistance in the reduction of data and estimation of experimental errors.

\section{METHODS. \\ Type of Soil and Method of Planting.}

Two types of soil were used throughout the experiments-except where otherwise stated, a loam and a peat.

The loam soil was brought from an unmanured bed in the Botanical Gardens. During the winter it was used in its unaltered form but during the spring and summer it was found desirable to add a little quartz sand in order to facilitate drainage and aeration. The reaction of this soil was neutral.

The peat soil was a pure sphagnum peat which was obtained from Saltersly Bog, Cheshire, in an air dried condition. The reaction was strongly acid, the specific acidity being $300\left(p_{\mathrm{H}}\right.$ value $\left.5 \cdot 5\right)$ on the scale given by the use of Wherry's (21) indicators. Both soils were sifted through a centimetre sieve before use, to obtain an evenly divided condition.

In order that experimental plants should be in as natural conditions as possible rooted plants were used in every case. During the earlier experiments the plants were grown in soils contained directly in glazed vessels, sealed with wax, according to the method of Briggs and Shantz (4). Later in the year the plants were grown in $5^{\prime \prime}$ diameter porous flower pots which were enclosed in metal shields when required for use. Six pound meat tins proved an admirable substitute for Ganong "Aluminium Shells" (10).

The plants were watered by means of a tube inserted through the wax, or through the lid of the tin to a depth of $2-4^{\prime \prime}$. The tube was inserted as near the centre of the root system as possible. It was found that the water admitted through the tube distributed itself fairly evenly throughout the pot after a few hours. No irregularities were noticeable due to uneven watering, when the readings were taken only once in 24 hours. An open aerating tube, of which the upper end projected above the soil level, was sunk to the bottom of the pot.

Control vessels-either glazed with a wax seal or in metal shields showed a loss of less than $0.5 \mathrm{gms}$. in three months.

\section{The Estimation of Transpiration.}

The rate of transpiration was estimated by measuring the loss in weight of the experimental vessels at stated intervals. The balances used for the smaller pots were sensitive to $0.02 \mathrm{gms}$.; those for the larger to $0.2 \mathrm{gms}$.

It was found that differences in response to external conditions on the part 
of the plants could be observed more clearly by using Livingston's (1 1) unit of relative transpiration. This is obtained by dividing the average unit transpiration of each group of plants by the rate of evaporation from a surface of the same area of a porous cylinder under the same conditions.

The unit transpiration was obtained by reducing the loss in weight recorded to that per square metre leaf surface per hour.

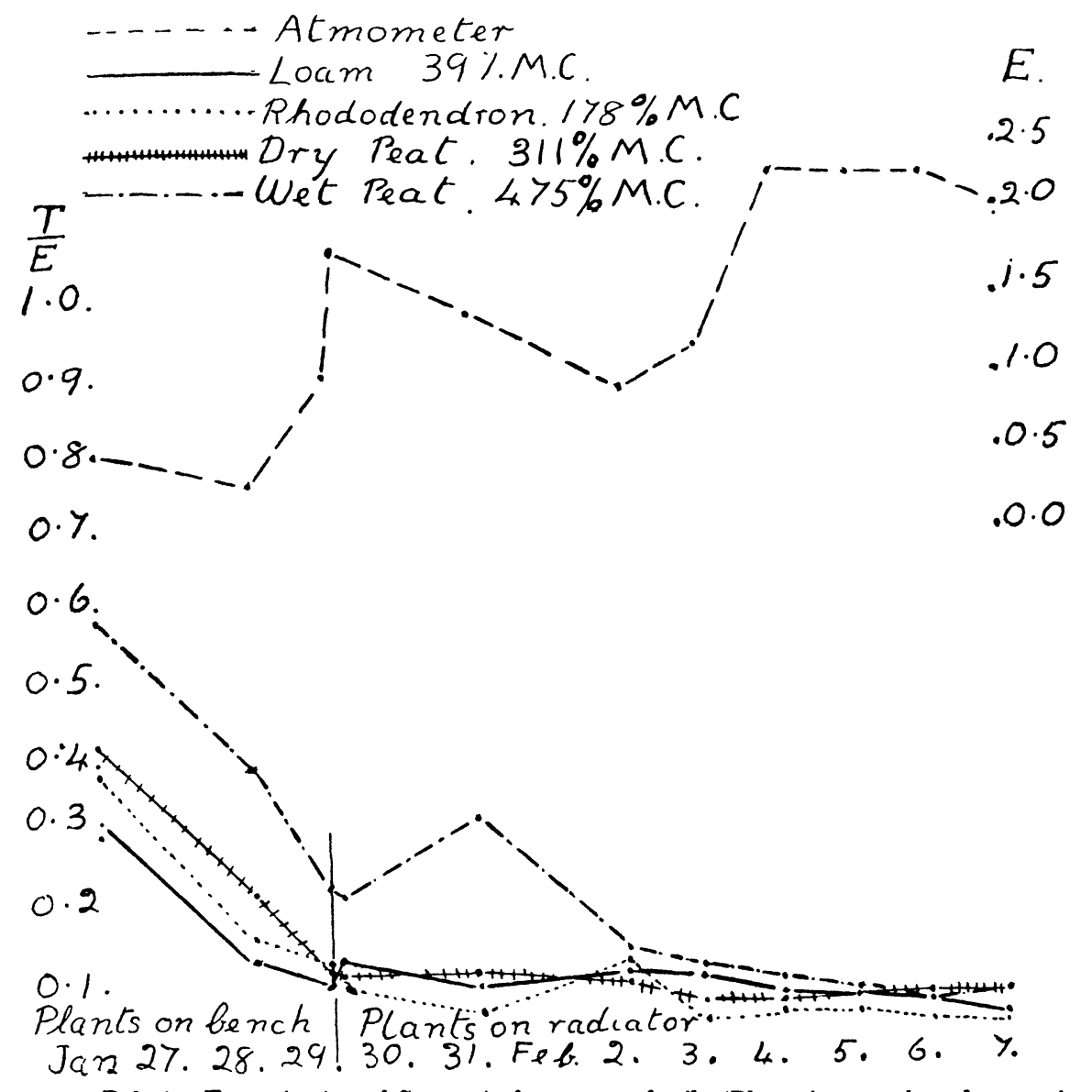

Fra. 1. Relative Transpiration of Savoys in four types of soil. (Plants in peat show decrease in relative transpiration due to increasing unhealthiness of roots.)

\section{Method of Estimating Leaf Surface.}

The method of estimating the leaf surfaces varied during the course of experimentation. When the plants could be sacrificed the leaves were cut off, placed under glass and traced with a planimeter, giving an error of $0.05 \mathrm{~cm}$. for leaves with plain margins.

When growth was active a method of estimation whilst the leaves were still on the plant became essential. A number of typical leaves varying in size 
from the most immature to the largest were removed from a plant similar to those used in the experiment. These were immediately placed under glass and the area of each obtained by means of a planimeter and kept as a standard.

A number of these standard leaves-from eight to 15 were placed between glass slips and kept for comparison.

When estimating the leaf surface of any given plant the number of leaves on the plant corresponding with each standard was calculated, and the number multiplied by the area of that standard. The total areas of the leaves approximating to each of the various standards were added and the sum considered to be the total leaf area of the plant. Each estimation was made at least twice and the average taken.

It was found that whilst these calculated areas were usually rather larger than those obtained by the former method, this increase remained constant for every plant and was approximately constant between plant and plant, provided that the same standards were used throughout the experiment. When plants of similar leaf surface were used in each type of soil the error arising from this method was never greater than 0.01 in the data of relative transpiration recorded in the tables.

\section{Estimation of Aerial Conditions.}

Temperature was recorded by a Richard's automatic thermograph, checked by Centigrade and Fahrenheit thermometers, whilst the relative humidity was recorded by a Richard's hygrograph. These instruments were found to be accurate to within $2^{\circ} \mathrm{F}$. and 5 per cent. saturation.

The total evaporating power of the air was recorded by means of a porous atmometer of the type described by Yapp (18) standardised by the method described by Thomas and Ferguson (15).

In the early experiments the plants were grown in a laboratory with a north light, but during the spring and summer all plants were grown in a greenhouse with a south aspect and lateral and overhead lighting. They were exposed to the direct rays of the sun.

A record was kept of the weather conditions prevailing between each reading.

\section{SoIL Conditions.}

During several experiments the temperature of the different types of soil was recorded but since this difference was never more than $5^{\circ} \mathrm{C}$., and did not exhibit any close connection with differences in the rate of transpiration of the plants in each type of soil, the record was not kept in later experiments.

The moisture content of each soil-calculated as a percentage of its dry weight (dried in an oven at $100^{\circ}$ C.), was estimated at the beginning and end of each experiment. The samples were obtained by mixing portions taken from three different places in each pot so that the result was the average moisture content of the soil in the pots. There was not, however, any apparent want of 
uniformity between the different portions of soil used at the end of the experiment.

\section{EXPERIMENTS.}

Preliminary experiments were undertaken in the winter with Triticum sativum, Rhododendron ponticum, Savoy cabbage, Pelargonium, Calluna and Eriophorum angustifolium. The plants were grown in various types of soil for periods varying from three weeks to three months.

In these experiments the soils were kept at constant water content, by watering up to the original weight after each reading. After some weeks they were allowed to dry until the plants showed signs of wilting, when the pots were turned out and the root systems of the plants examined.

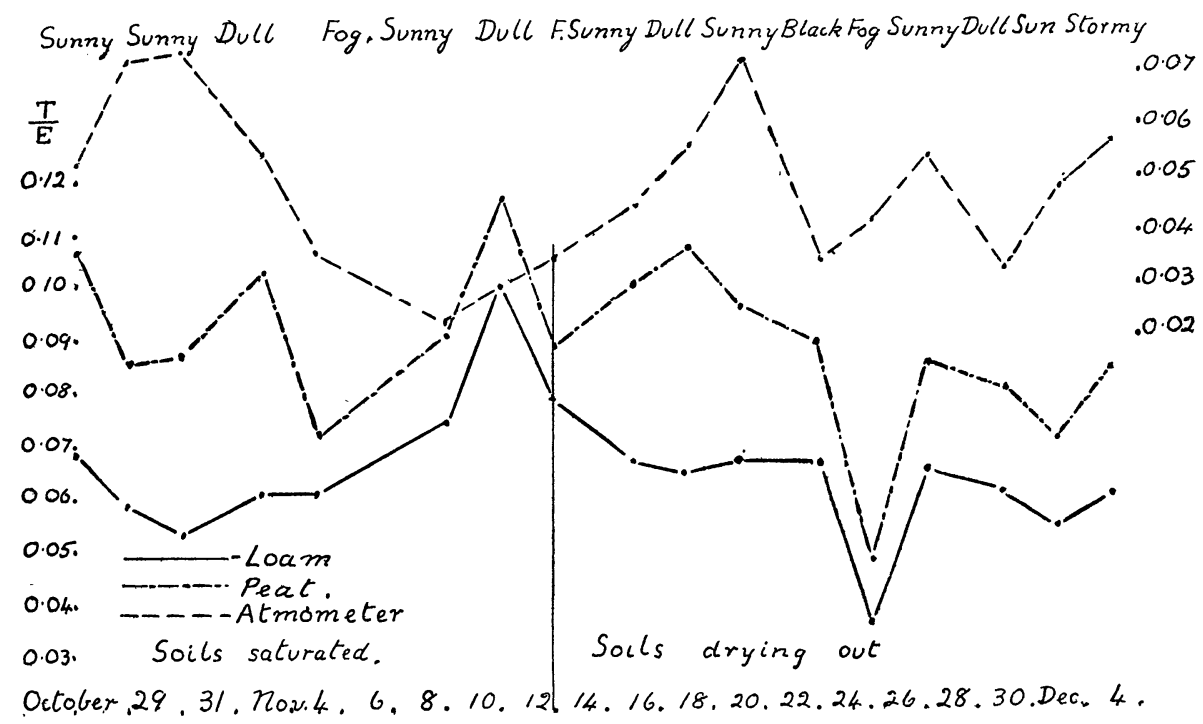

Fra. 2. Relative Transpiration, Rhododendron ponticum (four plants in each type of soil).

Four types of soil were used in preliminary experiments with Savoy cabbage: (1) loam (22.8 per cent. water content); (2) peat taken $3-5$ " below the surface of an "Eriophorum moor" on Chat Moss, Cheshire (water content 600 per cent. of weight dried at $100^{\circ}$ C.); (3) peat cut and dried on the Moss and then watered till its water content was 281 per cent. of the air dry weight; (4) very slightly decayed leaf mould taken from beneath rhododendron bushes on the edge of the Moss (water content 221 per cent. of the weight dried at $100^{\circ} \mathrm{C}$.

Plants were also grown simultaneously in water solutions of the loam and peat soil. These were made by shaking up equal volumes ( 2 gms. air dry peat or 14 gms. air dry loam) of finely divided peat or loam with 100 c.c. of distilled water. The mixtures were allowed to stand in corked flasks for three days and were occasionally shaken. They were filtered several times before use. Readings were taken 4-6 times a day between 9.30 a.m. and 5.30 p.m. in the earlier experiments and later only once a day. 
During this period the average evaporation from 100 sq. cms. of a Yapp atmometer was rarely above 0.9 c.c. per hour, whilst the temperature ranged between $41^{\circ} \mathrm{F}$. and $58^{\circ} \mathrm{F}$. Under these conditions the absolute rate of transpiration was very low. In order to increase this the plants were placed on a tray over a radiator, where they were exposed to an evaporation rate as great as $3 \cdot 3$ c.c. per hour and to a temperature varying from $50^{\circ}-80^{\circ} \mathrm{F}$. This increased the absolute transpiration but decreased the relative transpiration.

During several days extreme conditions were caused by immersing the vessels containing the plants in freezing mixture, whilst exposing the shoots to radiator conditions. Data for one of these experiments with Savoy cabbage are given in Table 1.

In all experiments under all conditions the rates of relative transpiration for the same species in different types of soil was slightly increased by an increased water content of the soil. These results are similar to those obtained by Yuncker (19) in his work on corn. A rise in the absolute and relative transpiration occurred in peat as compared with loam soil.

As a result of these preliminary experiments it appeared that the moisture content of the soil exercised a great influence on the rate of transpiration of the plants. It became advisable therefore to estimate the water content of peat soil which should be physiologically equivalent to any given moisture content of loam soil. To find this, determinations were made of the amounts of water present in each type of soil when wilting occurs.

Considerable difficulties were experienced because many herbaceous mesophytic plants which would show a definite wilting point, fail to establish successful root systems in peat; whilst plants which will produce healthy roots are of the woody or xerophytic type, which do not show a sharp wilting point.

Of the plants tried Betula alba and pubescens and Salix pentandra gave the most satisfactory results. The leaves of these plants do not droop suddenly, but the older leaves turn yellow and begin to dry at a fairly marked point which was taken to be the wilting point.

At this point, further, the curve of relative transpiration was found to show a marked and sudden rise which was independent of aerial conditions. Bakke $(\mathbf{1}, \mathbf{2})$ has shown that such a rise occurs at the wilting point of Helianthus.

Plants of birch in each soil wilting in May gave moisture content of the soil at wilting point as:

\begin{tabular}{|c|c|c|}
\hline \multicolumn{2}{|c|}{ Loam } & Peat \\
\hline \multicolumn{2}{|c|}{ 1. $13 \cdot 2 \%$ dry weight } & $188.5 \%$ \\
\hline 2. $12 \%$ & , & $200 \%$ \\
\hline 3. $16.5 \%$ & , & $131 \%$ \\
\hline 4. $13 \%$ & ", & $177.5 \%$ \\
\hline 5. $13.7 \%$ & ", & \\
\hline Averag & $6 \%$ & ge $174 \cdot 2$ \\
\hline
\end{tabular}

This gives a ratio of $1: 12 \cdot 8$ at the wilting point of birch. 
Kathleen M. Thatcher

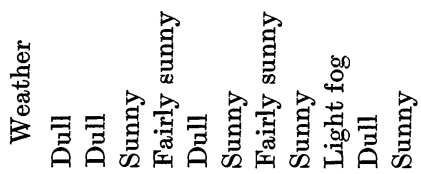

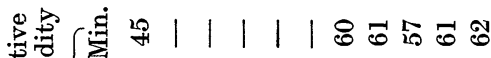

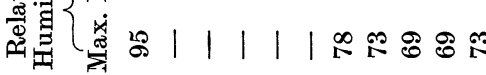

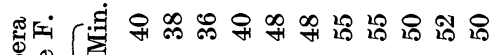
의의

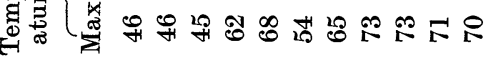

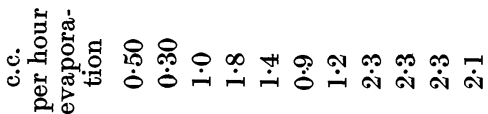

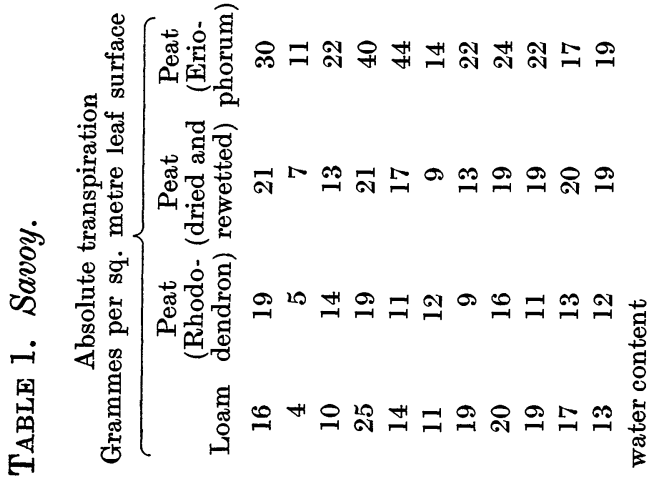

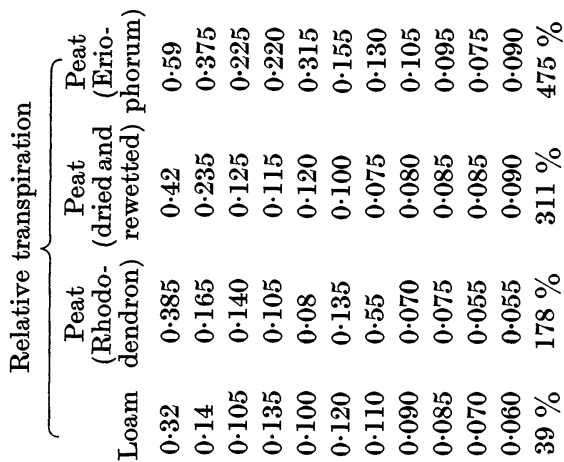

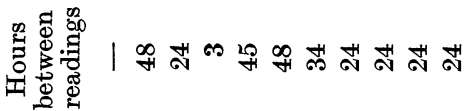

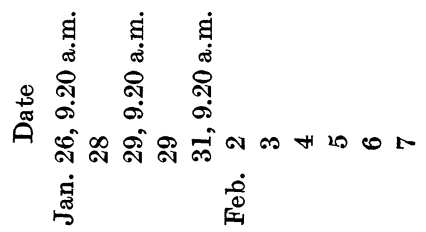


When Salix pentandra wilted under more extreme conditions in August the water content at that point was found to be 10.2 per cent. and 134 per cent. for peat and loam respectively, giving a ratio of $1: 13 \cdot 1$ respectively.

Thus although the actual percentage of water present in the soils at the wilting point was different in the two cases, the ratio of the moisture present in loam and peat was practically identical.

When both soils were saturated by standing the pots containing them for two hours in water and then draining until dripping ceased, the soil moistures were found to be $37 \cdot 1$ per cent. and 486 per cent. giving a ratio of $1: 13$, which is practically that of the wilting points.

From these experiments, though at present the results are based on a rather small number of examples it would appear that the physiologically equivalent amount of water for the two soils would be in a proportion of 1 in loam to 13 in peat. Further experiments on this point are being carried out.

During later experiments the soils were always used with the moisture contents in this proportion.

The experiments with Savoy were not repeated as the plants showed an unhealthy development of the root system, but experiments with eight plants of Rhododendron ponticum grown for a period in saturated peat and in loam soil and then allowed to dry out, showed that the peat soil increased the transpiration of the plants grown in it to a considerable extent.

When the soils were nearing the wilting coefficient two of the plants were placed on a radiator with the vessels immersed in ice in the same manner as described for Savoys. It was found that the plants in peat soil, in spite of the greater rate of transpiration were able to withstand extreme conditions of high temperature and cold dry soil as effectually as those plants grown in loam. The results of this experiment are given in Table 2 and the curves constructed from these tables in Fig. 2.

During spring and summer small birch plants $1 \frac{1}{2}-2 \mathrm{ft}$. in height and rooted cuttings of Salix pentandra and Salix cinerea were grown in soils varying in water content from saturation to a point well below the wilting point of the older leaves. In these experiments 22 birches, 44 rooted cuttings of Salix pentandra and 26 rooted cuttings of Salix cinerea were used.

All experiments gave comparable results, confirming those obtained from the preliminary experiments.

The following experiments are typical:

Experiment I. Salix pentandra rooted cuttings were grown in:

A. Glazed vessels containing (1) peat soil 326 per cent. water content ${ }^{1}$, (2) loam soil $25 \cdot 5$ per cent. water content.

Six vessels each containing two cuttings were used for each soil.

1 The water contents are in all cases given in percentages of weight of the soil after drying at $100^{\circ} \mathrm{C}$. 
Kathlehe M. Thatcher

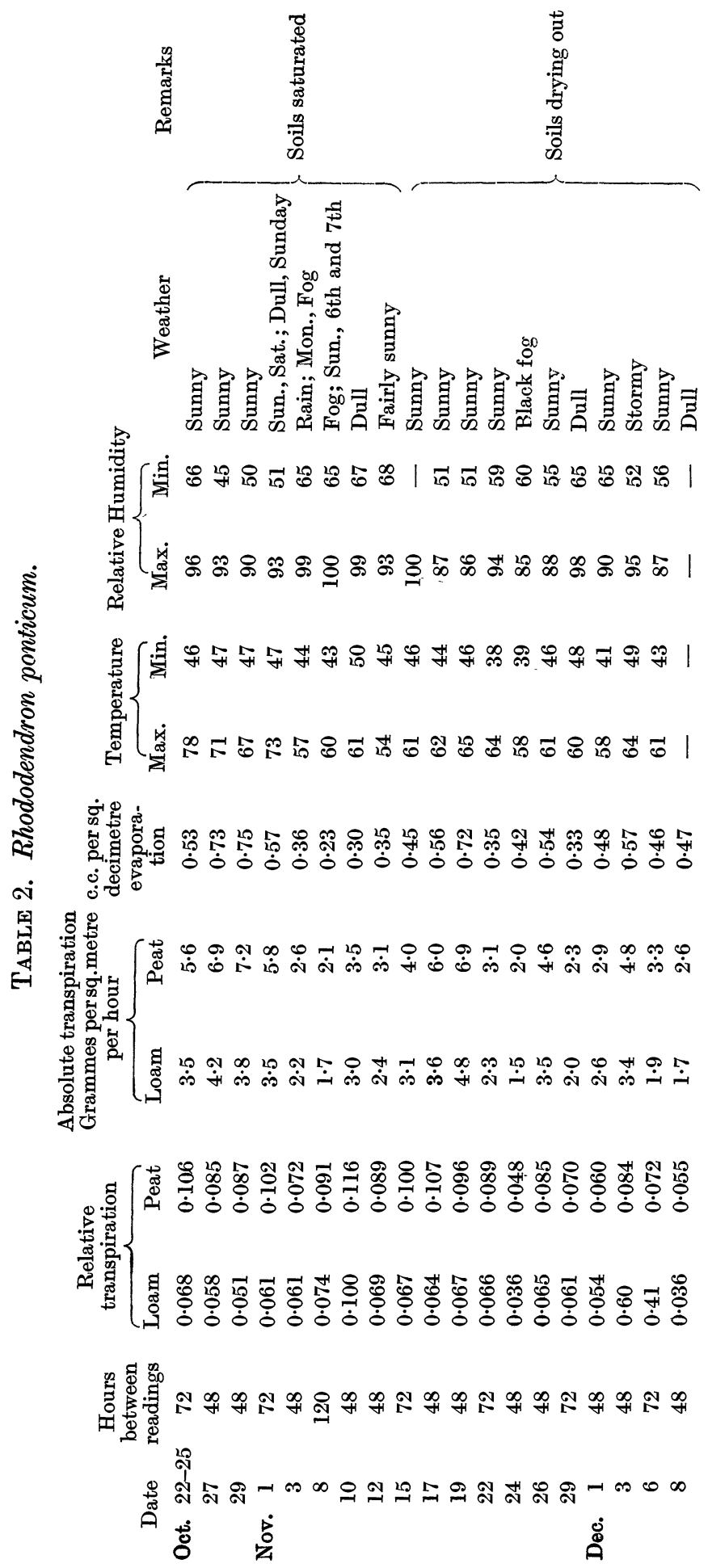



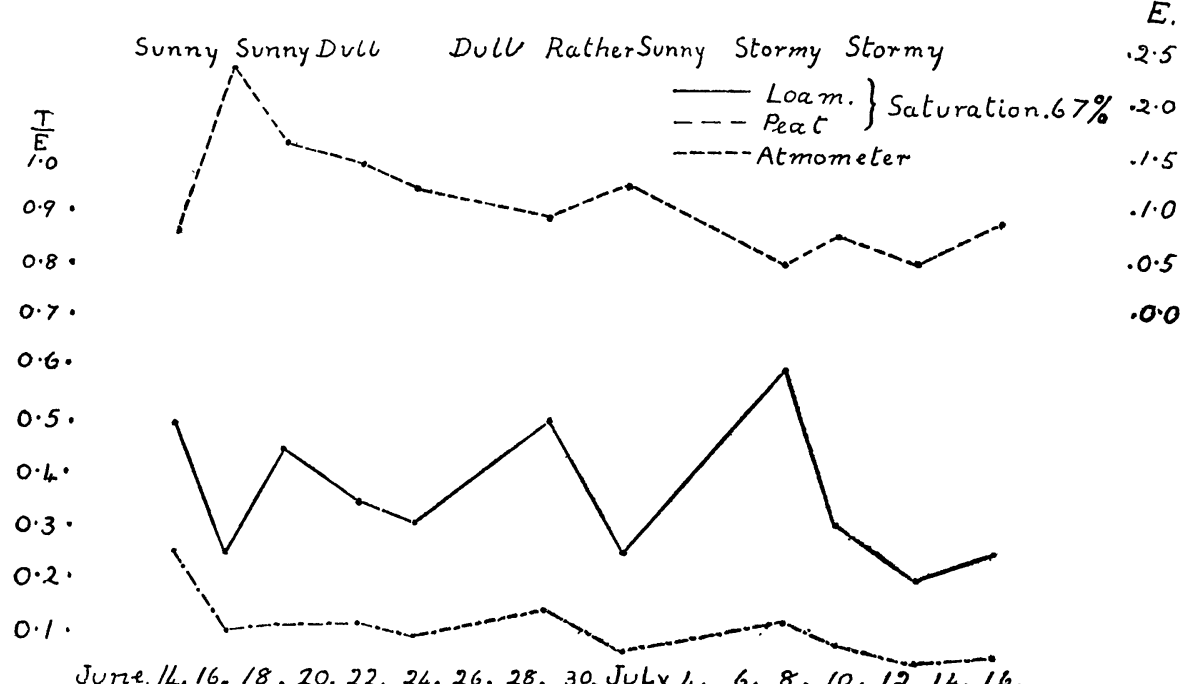

June.14.16. 18. 20. 22. 24. 26.28. 30. JuLy 4. 6. 8. 10.12.14. 16.

FIG. 3. Relative Transpiration, Salix pentandra (grown in glazed vessels).

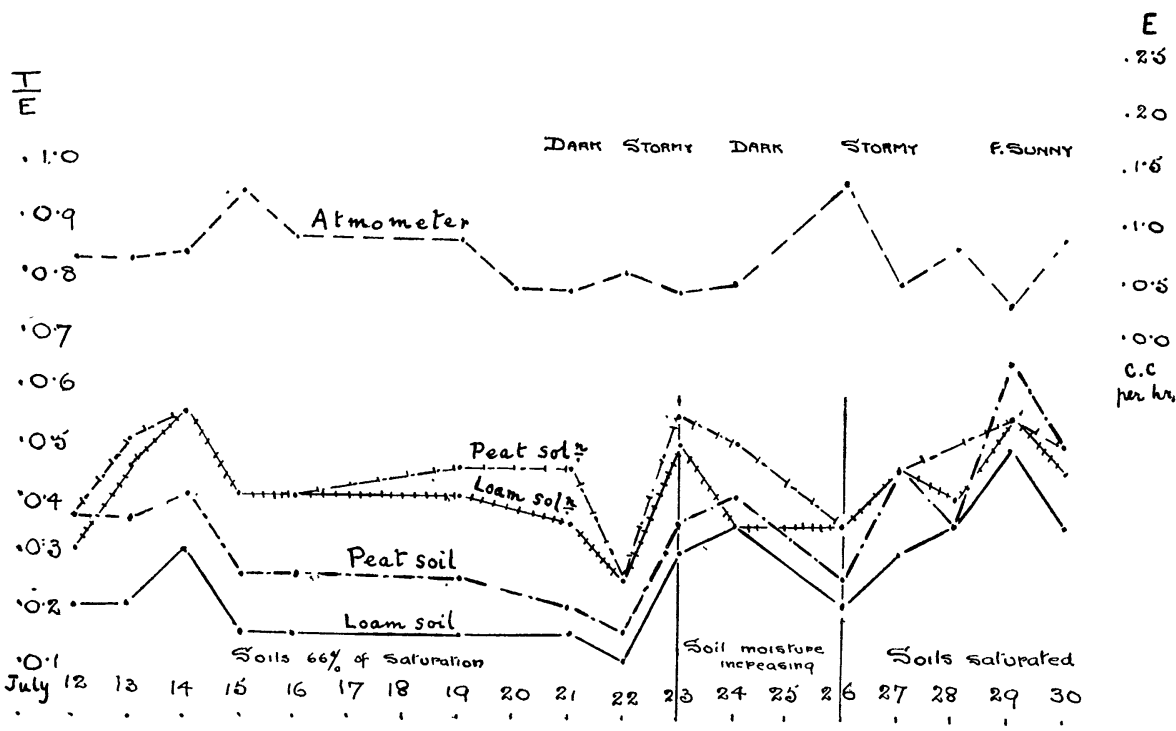

Fra. 4. Relative Transpiration, Salix pentandra grown in drained loam and peat soils and in loam and peat solutions. 
B. Porous flower pots enclosed in metal shields containing (1) peat soil with 326 per cent. water content, (2) loam soil with $25 \cdot 5$ per cent. water content.

In each case three,pots were used. Two of these contained two plants and the third three.

C. Corked bottles containing the soluble constituents (1) of peat, and (2) of loam obtained by shaking up peat and loam respectively with water.

Four cuttings were used in each solution.

The solutions were made up by using the weight of peat or loam necessary to give 0.3 gms. dissolved material per 1000 c.c. of water. This was obtained by adding $10 \mathrm{gms}$. of air dried peat or $40 \mathrm{gms}$. of air dried loam to every 1000 c.c. water. The mixtures were well șhaken and filtered after standing $2 \frac{1}{2}$ hours.

A was carried on immediately before $B$ and $C$ which were simultaneous. In all cases the plants were placed in a greenhouse with a south light. This was kept at a relative humidity of above 40 per cent. saturation by means of a continuous spray of water which played near the experimental table during sunny days. If the relative humidity was allowed to fall below this point the leaves of all the plants turned brown and dried.

A was continued for three weeks. During this period the plants in peat did not grow well, no new shoots were formed, and the transpiration began to fall early. At the end of the time an examination of the underground parts showed that the roots had failed to establish themselves. The plants in loam examined at the same time had formed extensive root systems and produced new leaves on the shoots, except one plant which failed to establish itself and behaved exactly like the plants in peat.

This experiment exhibited a marked depression in the absolute, and therefore in the relative transpiration of the plants in peat as compared with that of those in loam.

Experiments B and C were carried on simultaneously under similar conditions to A. After 14 days the soils in B were watered up to saturation point. At the end of the experiment the plants in both types of soil and solution were equally healthy and had developed extensive root systems. In these experiments the relative transpiration in peat soil or solution was greater than that in loam soil or solution.

In Tables 3, 4 and 5 are given data of these experiments and also of a previous experiment in which Pfeffer's culture solution ( $0 \cdot 3$ gms. per 1000 c.c. water) was used as well as the two soil solutions.

The experiment $B$ falls into three periods. For the first 12 days the soil moistures are 67 and 68 per cent. saturation, during three days the soil moistures were gradually increasing, still in the ratio $1: 13$, and for the last nine days the'soils were saturated.

Journal of Ecology IX 


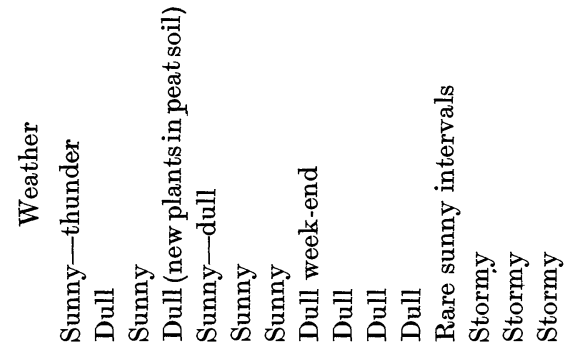

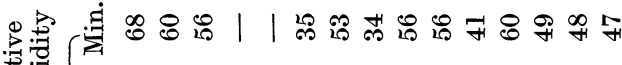

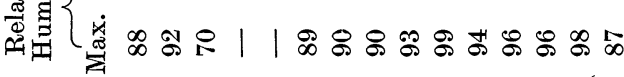

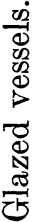

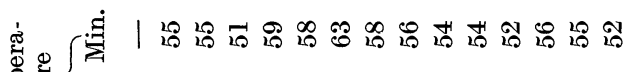

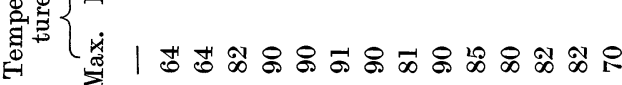

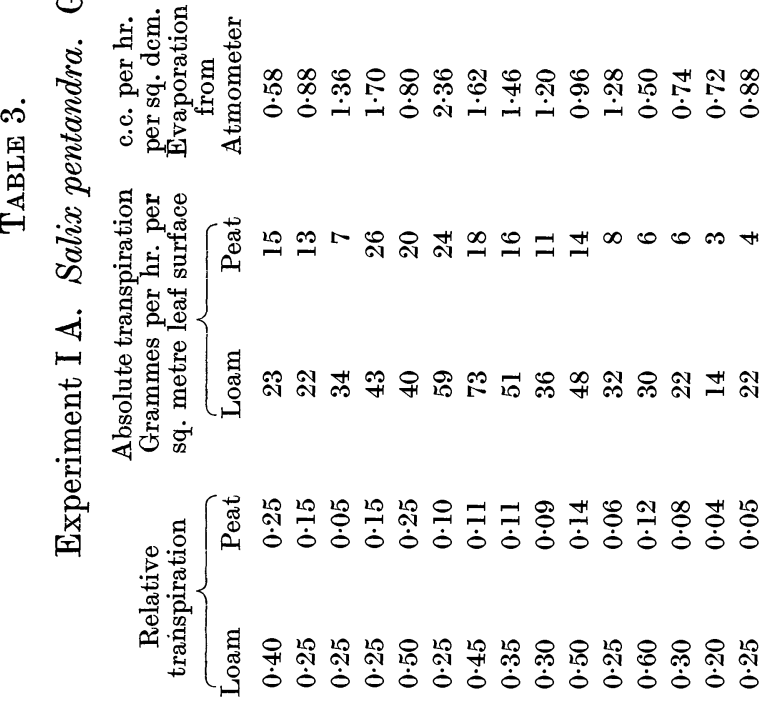

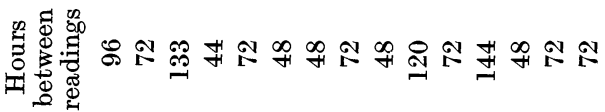

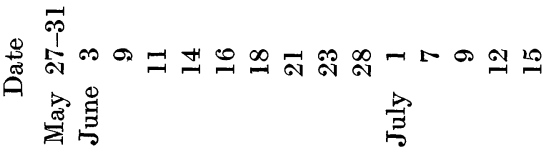


Kathleen M. Thatcher

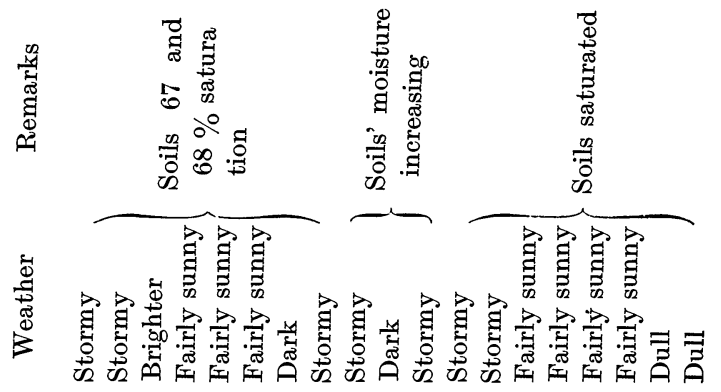

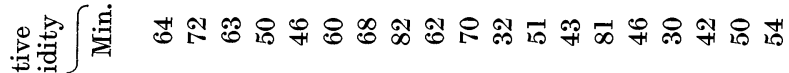
正

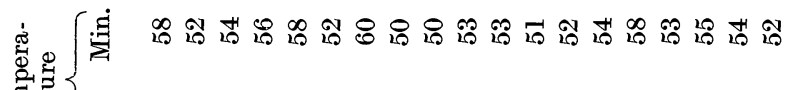
承

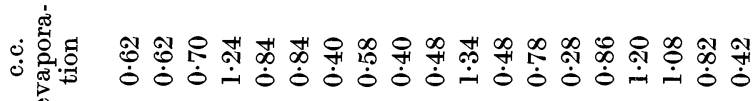

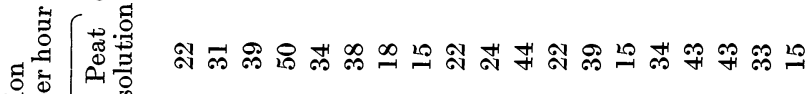

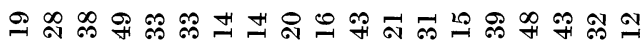
สีสัง ๆ

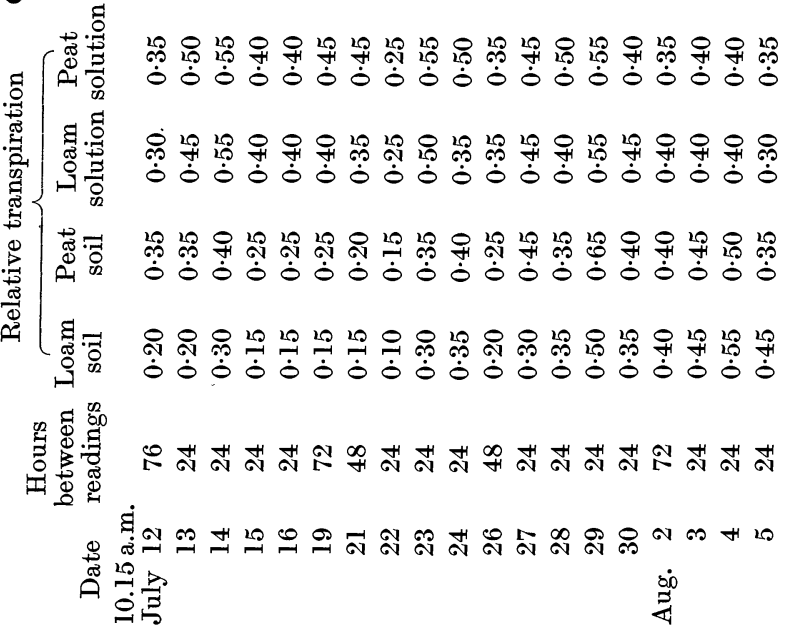
告 
During the whole period the transpiration in peat is higher than that in loam. With the increase in water content there is an increase in the relative transpiration of both groups of plants.

A comparison between the effect of drained peat and fairly dilute peat solution in this experiment and that of the undrained peat in the last experiment is interesting.

\section{TABLE 5.}

Salix pentandra in soil and culture solutions.

\begin{tabular}{|c|c|c|c|c|c|c|c|c|}
\hline \multirow[b]{2}{*}{ Date } & \multirow{2}{*}{$\begin{array}{l}\text { Hours } \\
\text { between } \\
\text { readings }\end{array}$} & \multicolumn{3}{|c|}{ Relative transpiration } & \multicolumn{3}{|c|}{$\begin{array}{l}\text { Absolute transpiration } \\
\text { Grammes per sq. metre }\end{array}$} & \multirow{2}{*}{$\begin{array}{l}\text { c.c. per hr. } \\
\text { per sq. dcm. } \\
\text { Evaporation } \\
\text { from } \\
\text { Atmometer }\end{array}$} \\
\hline & & Loam & Peat & Culture & Loam & Peat & Culture & \\
\hline May 24 & 72 & $0 \cdot 45$ & $0 \cdot 40$ & $0 \cdot 30$ & 40 & 36 & 27 & 0.9 \\
\hline 25 & $22 \cdot 5$ & $0 \cdot 31$ & $0 \cdot 30$ & $0 \cdot 25$ & 43 & 41 & 34 & $1 \cdot 36$ \\
\hline 26 & 24 & $0 \cdot 30$ & $0 \cdot 25$ & $0 \cdot 20$ & 35 & 31 & 24 & $1 \cdot 18$ \\
\hline 27 & $29 \cdot 5$ & $0 \cdot 28$ & $0 \cdot 28$ & $0 \cdot 25$ & 17 & 17 & 15 & $0 \cdot 62$ \\
\hline 31 & 92 & $0 \cdot 30$ & $0 \cdot 30$ & $0 \cdot 35$ & 17 & 17 & 20 & 0.58 \\
\hline June 1 & 24 & $0 \cdot 40$ & $0 \cdot 40$ & $0 \cdot 45$ & 20 & 20 & 23 & 0.50 \\
\hline 2 & 24 & $0 \cdot 19$ & $0 \cdot 17$ & $0 \cdot 10$ & 25 & 22 & 13 & $1 \cdot 30$ \\
\hline 3 & 24 & $0 \cdot 30$ & $0 \cdot 30$ & 0.35 & 25 & 25 & 29 & $0 \cdot 82$ \\
\hline 4 & 24 & $0 \cdot 30$ & $0 \cdot 30$ & 0.25 & 34 & 34 & 29 & $1 \cdot 14$ \\
\hline
\end{tabular}

When the peat was drained and fairly well aerated the plants remained perfectly healthy, and in every respect were entirely similar to those plants grown in loam. The transpiration throughout the experiment was greater in peat than in loam. When grown in the undrained peat the plants were unable to produce new roots or to form any intimate connection with the soil, and the transpiration was considerably less than that of the plants grown in loam.

The plants grown in soil solutions showed a higher rate of relative transpiration than those in the soils when the water content of the soils was only 67 per cent. saturation, but showed a similar or slightly lower rate when the soils were fully saturated. In this case also the rate of transpiration in peat was greater than in loam. The decrease during the last few days of the experiment was probably due to unhealthy root conditions, as algae were beginning to appear in the solutions during that period.

When plants were grown in culture solution as well as in loam and peat solutions the rate of transpiration in all three was approximately equal, but in this case the buds of shoots used were not well expanded and the actual amount of water lost per cutting was small.

\section{Experiment II.}

A. In this experiment seven small birches were grown in each type of soil. The soils were saturated at the commencement of the experiment. At the end of a week the soils were allowed to dry out until the youngest leaves were beginning to dry.

At first the relative transpiration was lower in the peat than the loam soil, 
this was probably due to unhealthy conditions of the roots as plants kept in saturated peat for some time were unhealthy. As the soils became drier the relative transpiration in the peat soil rose above that of the loam and remained in that position until the wilting point.

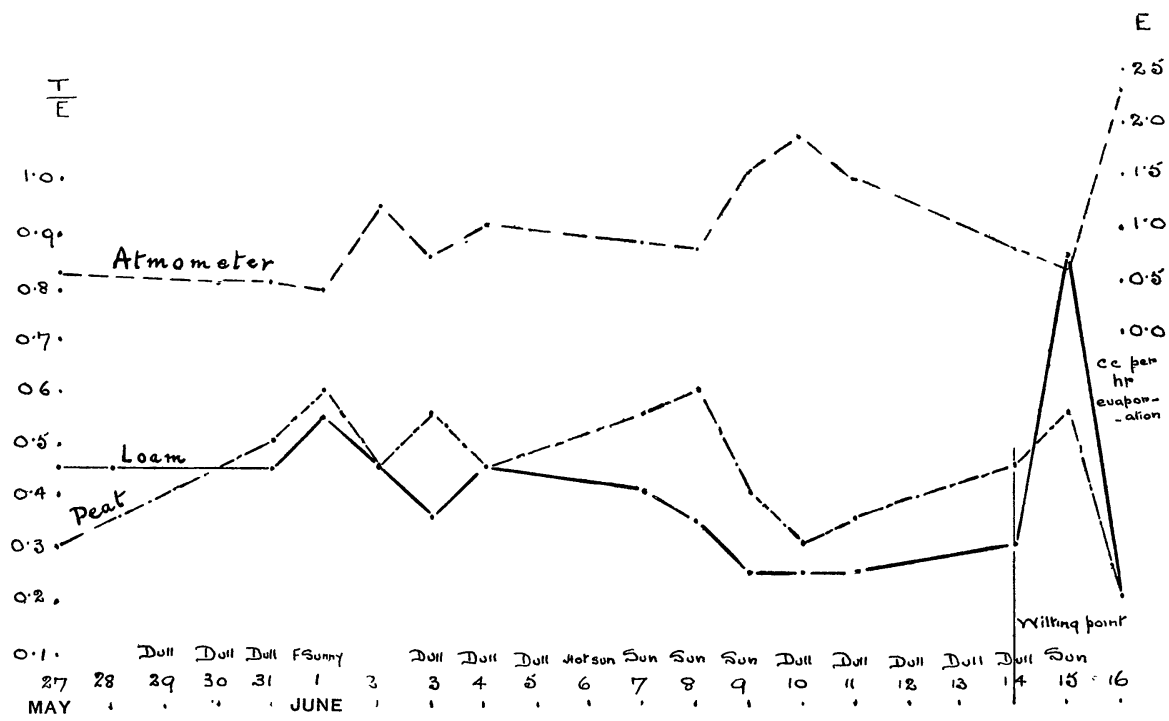

Frg. 5. Rélative Transpiration. Betula sp. grown in saturated peat and loam soils and allowed to dry out.

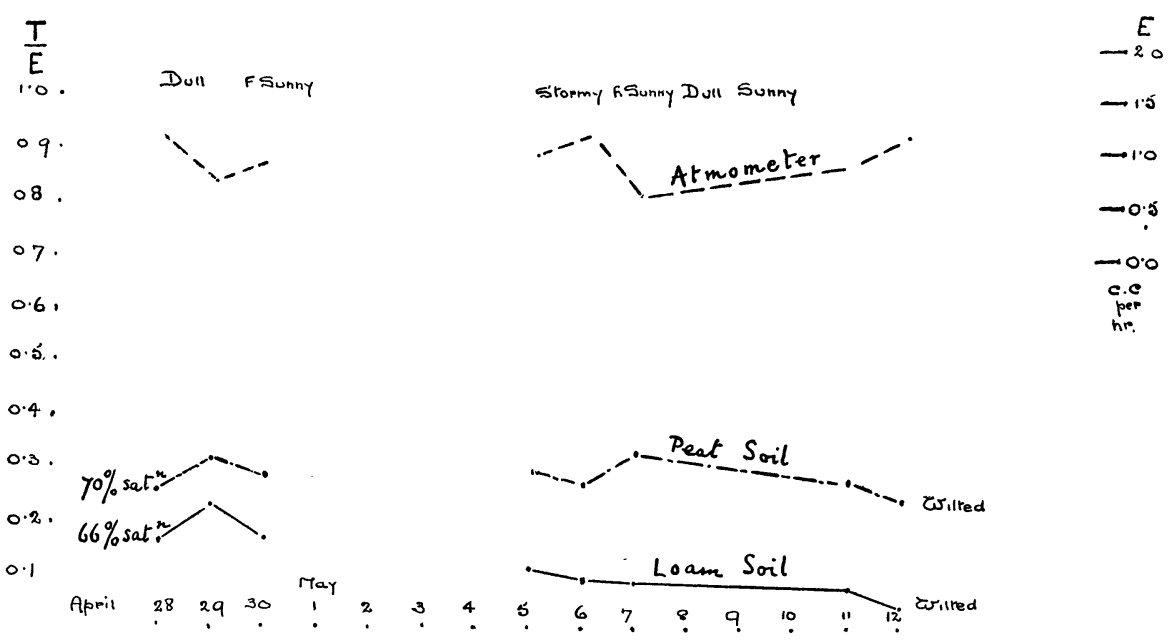

Frg. 6. Relative Transpiration. Betula sp. in loam and peat soil allowed to dry out to wilting point.

After this point the plants in peat tended to lose water more slowly than those in loam.

B. In an experiment where different plants were placed in soils-peat 


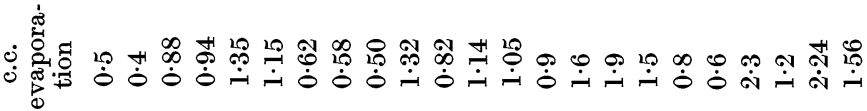

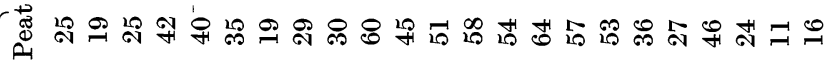
急

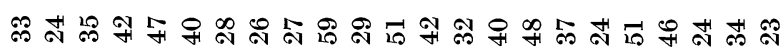

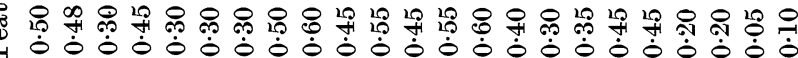
(1)

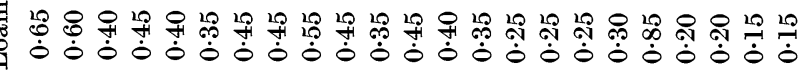

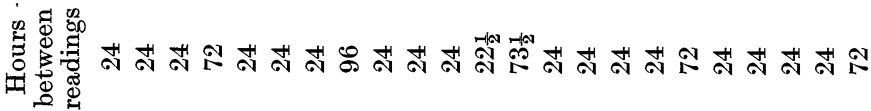

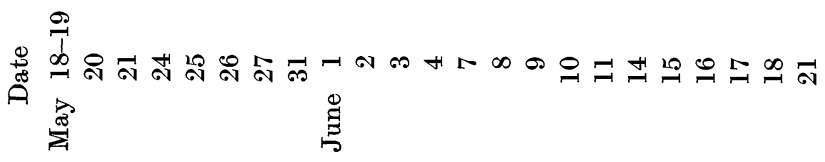


70 per cent. saturation, loam 66 per cent. saturation-and allowed to wilt, the transpiration in peat soil was considerably greater than those in loam.

Data of these experiments are given in Tables 6 and 7 and curves in Figs. 5 and 6.

The results obtained from these experiments may be stated shortly as follows:

In all experiments the direct effect of the peat soil was to increase the transpiring power of the plants grown in it, as compared with that of similar plants grown in loam soil under the same conditions.

The only cases in which the transpiration was considerably reduced in peat soil were when the plants showed very unhealthy roots.

\section{TABLE 7.}

\section{Experiment 2 B. Birches.}

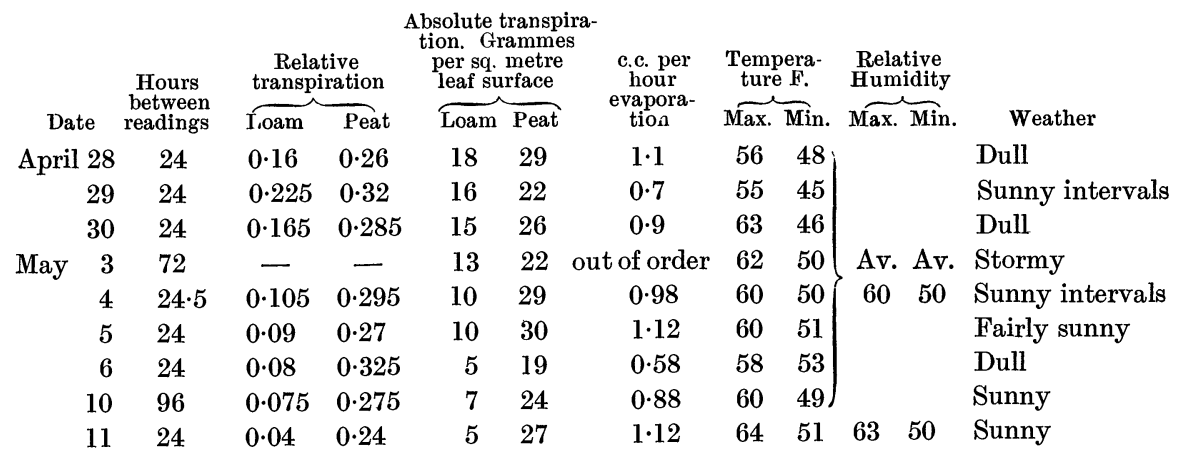

In both types of soil the relative transpiration of the plants varied similarly with three conditions:

(a) With an increase in moisture content of the soil there was an increase in the relative transpiration and vice versa.

(b) The occurrence of unhealthy roots caused a marked decrease in the relative transpiration of the plants.

(c) The plants were less sensitive to a change in the evaporating power of the air than was the white porous atmometer with which they were compared, so that a rise in the evaporation rate was accompanied by a depression in the relative transpiration and vice versa.

\section{The Effect of Peat on Growth.}

During the course of the investigation several interesting results of the effect of peat on the growth of the plants were obtained. Further work is being carried out on this aspect of the problem, but those results already obtained are sufficient to have a distinct bearing on the interpretation of the transpiration data. 
Observations have been made on wheat, Savoy cabbage, Pelargonium ("scarlet geranium "), Helianthus annuus and others, whilst records were kept of the development of the shoot and root system in all transpiration experiments.

It was found that in the case of wheat no new roots were formed when seedlings $5 \mathrm{cms}$. in height were transplanted into pure peat, and soil three parts peat to one part loam, contained in glazed vessels. In soil half peat, half loam, roots developed but were stunted, whilst in soil 1 part peat to 3 loam and pure loam soil the seedling grew perfectly healthily.

Exactly the same phenomena occurred when small Savoy plants were transplanted into peat and loam soils. It was noticeable here that the roots and the base of the stem showed a tendency to rot away when grown in wet peat. Exactly the same pathological symptoms showed themselves when Savoys were grown in water culture solution or in very wet undrained loam soil.

Similar results were obtained when rooted cuttings of Pelargonium were grown in peat and loam soils of varying water content. The plants in wet loam and peat soil were equally stunted and showed a tendency to rot whilst in drier undrained soil the stunting was less marked.

The case of Epilobium hirsutum is especially interesting. In May four plants of approximately equal size and root development were planted in porous pots, two of which contained peat and two loam soil. They were left to grow side by side in the greenhouse for two months. At the end of that period the two plants in loam had reached a height of 44 and $49 \mathrm{cms}$. and one plant was producing flowers. The largest leaves were $6 \mathrm{cms}$. and the internodes varied from $2 \cdot 5-3 \mathrm{cms}$. in length. One plant in peat soil had died. The other was only $18 \mathrm{cms}$. in height and showed no signs of flowering. The largest leaves were $3 \mathrm{cms}$. in length and the majority were $0.5 \mathrm{~cm}$. They were no thicker than those of the plants in loam. The internodes were never longer than $0.5 \mathrm{~cm}$.

When the root systems were examined it was found that whilst the plants in loam had produced numerous roots and become almost pot-bound, the plant in peat had not formed any new roots or any intimate connection with the soil.

This experiment was repeated later with seven plants in each type of soil. Six of the plants in peat showed the same marked stunting as that noticeable in the first experiment, but the seventh was entirely similar to the plants in loam. The roots of the six were shrivelled and no new ones formed, whilst those of the seventh were well developed and healthy. This would point to the fact that the difficulty in forming an effective root system is the primary cause of the stunting of the shoot in Epilobium hirsutum, since when a healthy root system is formed the shoots are exactly similar to those of plants grown in loam.

The behaviour of Salix pentandra when grown in drained and undrained peat has already been mentioned; further information was obtained by growing 
cuttings in peat and loam soil solutions containing 0.3 parts of dissolved material per 1000 c.c. distilled water.

In both solutions roots which had been formed before transplanting remained in a similar condition. In the loam solution the old roots produced numerous new lateral roots, and also a large number of adventitious roots emerged through the bark at the base of the cutting as early as the fourth day of the experiment. These attained a length of $15 \mathrm{cms}$. in three weeks.

In the peat solution all the roots remained healthy but very few new roots, either lateral or adventitious, were initiated and those that were produced never grew longer than $4 \mathrm{cms}$. in the three weeks of the experiment.

The inference drawn from these experiments is that peat has a stunting effect on the root system of Salix pentandra, rendering it difficult for the plant to produce new roots. This effect is accentuated by lack of drainage and aeration, so that, whilst in drained fairly damp peat soil, the plant is able to overcome the difficulty and grow healthily, in undrained soil it is unable to stand the shock of transplanting and dies.

In the case of the solutions the shock of transplanting is not so great and the plant is able to produce healthy growing shoots and to maintain a rate of transpiration greater than that of the plants in loam solution without any signs of wilting, in spite of the poorer development of roots.

In the case of Salix cinerea the roots were equally healthy in both solutions.

Birches grown in peat soil produced root systems which were as well developed as those in loam soil, and the same was the case with sycamore (Acer pseudo-platanus) both plants producing numerous root hairs in either soil.

\section{ConcLusions.}

It is noticeable throughout the investigation that, whenever a plant is able to produce a healthy root system it is able to obtain sufficient water from the peat soil to maintain a higher rate of transpiration than that maintained by the same species of plant growing under identical conditions in loam soil.

This was found to be the case when both soils were very moist or when the water content of the soils was reduced to wilting point, even during experiments in which the plants were exposed to conditions which were more severe than those usually occurring in English peat bogs.

The plants in peat were equally able to survive sudden increases in the evaporating power of the air which occurred when they were removed from the laboratory bench to a radiator.

The wilting coefficient of birch and willow in peat averaged 172 per cent. and 134 per cent. of the weight dried at $100^{\circ} \mathrm{C}$. After a long hot dry spell last June the peat at Chat Moss, Cheshire, was supersaturated at a depth of $6^{\prime \prime}$ and contained 300 per cent. of its dry weight in water at a depth of $2^{\prime \prime}$.

These facts seem to indicate that the "xerophilous" structure as a means 
of checking water loss by transpiration is not an essential adaptation to a peat bog community.

But it is noticeable that very few mesophytic plants, of those at present under observation, will establish themselves in a peat substratum, even when it is partially drained and aerated. The plants which produced really healthy and extensive root systems were all woody plants-with the exception of the single plant of Epilobium hirsutum.

The problem therefore seems to turn on the power of the plants to produce healthy roots in peat soil. The fact that, almost without exception the only plants of those experimented upon which were able to produce healthy roots were not typical mesophytes but woody plants may be of significance, but the question of any correlation between the power of resistance of roots to the unfavourable conditions of peat soil and the possession of xerophytic characters is still awaiting solution.

\section{Summary.}

1. Transpiration data were obtained by weighing rooted plants.

2. Plants were grown in peat and loam soils or in peat and loam soil solutions.

Several plants were used in each type of medium and the average transpiration per square metre leaf surface of the plants in the different media was compared. A comparison between the average relative transpiration of the groups of plants in the different media was also made.

3. Material was used which had been growing in the different types of soil for several months before the experiment, and also some which was transplanted immediately before use. No difference in behaviour was noticeable between the two types.

4. The chief factors influencing the relative transpiration of the plants were four:

\section{(a) The evaporating power of the air.}

To a change in this the plants were less sensitive, than was the white porous atmometer with which they were compared, so that an increase in the rate of evaporation from the atmometer was accompanied by a decrease in relative transpiration and vice versa, irrespective of the type of medium in which the plant was growing.

(b) The moisture content of the soil.

The relative transpiration increased with an increase in the moisture content of the soil and vice versa.

\section{(c) The type of soil.}

The direct effect of the peat was to increase the transpiration rate as compared with that of the plants grown in loam of the same per cent. saturation. The increase in the green weight of the plants during the experiments was the same in both types of soil. 


\section{(d) Healthy development of roots.}

In the case of both soils unhealthy root systems caused a marked decrease in the transpiring power of the plants.

5. Peat soil, largely because of the lack of drainage and aeration, causes unhealthy development of roots and hence indirectly stunting reduced transpiration and death.

6. There is no indication that xerophytic characters are in any way necessary in the case of those plants which can produce healthy roots in peat soil.

\section{LITERATURE:}

(1) Bakke, A. L. "The Index of Foliar Transpiring Power as an Indicator of Permanent wilting in plants." Bot. Gaz. 60, 1915, 2, p. 314.

(2) Bakke, A. L. "The Determination of Wilting." Bot. Gaz. 66, 1918, 2, p. 86.

(3) Bakke, A. L. "Studies on the Transpiring Power of Plants as Indicated by Standardised Hygrometrical Paper." This Journal, 2, 1914, p. 145.

(4) Briggs and Shantz. "The Wilting Coefficient of Plants and its Indirect Determination." U.S. Dept. Agric. Bureau Plant Industry Bull. 23; Bot. Gaz. 1912, 1, p. 180.

(5) Briggs and Shantz. "Daily Transpiration through the Normal Growth Period and its Correlation with the Weather." Journ. Agric. Research, 1916, 7, p. 155.

(6) Burns, G. P. "Edaphic Conditions in the Peat Bogs of Southern Michigan." Bot. Gaz. 52, 1911, p. 105.

(7) Cox, H. J. "Physical Conditions in Sphagnum Bogs." Review by B. Rigg. Bot. Gaz. 61,1916, p. 159.

(8) Dachnowski, A. Peat Deposits of Ohio; also Bot. Gaz. 46, 47, 49, 52.

(9) Gates, F. C. "Winter as a Factor in the Xerophily of Certain Evergreen Plants." Bot. Gaz. 57, 1914, p. 445.

(10) Ganong, W. F. "New Normal Appliances for use in Plant Physiology III." Bot. Gaz. 41, 1906, p. 212.

(11) Livingston, B. F. "Resistance by Leaves to Water Loss." Plant World, 16, 1913, p. 1.

(12) Livingston, B. E. "Relation of Desert Plants to Soil Moisture and Evaporation." Bot. Gaz. 40, 1905, p. 175.

(13) Livingston, B. E. "Physical Properties of Bog Water." Bot. Gaz. 37, 1904, p. 383.

(14) Rigg, G. B. "Summary of Bog Theories." Plant World, 19, 1916, p. 310.

(15) Thomas, Nesta and Ferguson, A. "On the Reduction of Transpiration Observations." A.B. 31, 1917, p. 241.

(16) Transeau, E. N. "Geographical Distribution and Ecological Relations of the Bog Plant Societies of Northern America." Bot. Gaz. 36, 1903, p. 401.

(17) Transeau, E. N. "Bogs and Bog Flora of the Huron Valley." Bot. Gaz. 40, 41, 1906, pp. 1-17.

(18) Yapp, R. H. "The Stratification of the Vegetation of a Marsh and its Relation to Evaporation and Temperature." A.B. 23, p. 275.

(19) Yuncker, T. G. "The Study of the Relation of Soil Moisture to Transpiration and Photosynthesis in the Corn Plant." Plant World, 19, 1916, p. 151.

(20) Waterman, W. G. "Development of the Root Systems under Dune conditions." Bot. Gaz. 68, 1919, p. 22.

(21) Wherry, E. T. "Soil Acidity and a Field Method for its Measurement." Ecology, r, 1920 , p. 160 . 